ARTIGO

\title{
As estratégias de governamento identitário na Educação*
}

\author{
Patrícia Gräff a \\ Maura Corcini Lopes ${ }^{b}$
}

\section{Resumo}

O texto problematiza as estratégias de governamento identitário operadas na Educação, na Contemporaneidade. No cruzamento entre os estudos de Michel Foucault e as teorizações que filiam-se ao pensamento social contemporâneo, articula o governamento como ferramenta para o exercício analítico produzido sobre seis publicações do Ministério da Educação, que compõem a coleção Educação para Todos. Mostra duas estratégias de governamento identitário delineadas nas políticas educacionais: a produção da tolerância e a inversão do estigma, que assumem, como fim, o esmaecimento das práticas de discriminação. Conclui-se, por fim, que a inversão parcial do estigma inviabiliza a incorporação da tolerância nos relacionamentos entre os indivíduos, fazendo com que essas estratégias não produzam os efeitos esperados.

Palavras-chave: Identidade cultural. Tolerância. Discriminação. Educação.

A cada hora e meia, uma mulher é assassinada por um homem no Brasil, apenas por ser mulher (DEBELAK; DIAS; GARCIA, 2015, s/p).

Diariamente, mais de dez jovens entre 16 e 17 anos são mortos [no Brasil], dos quais 93\% são negros (WELLE, 2015, s/p).

A cada 27 horas, um homossexual é assassinado no país. Só no ano passado, foram registradas 318 mortes de gays, travestis, lésbicas e bissexuais (AZEVEDO; BRETAS, 2016, s/p).

* O artigo recebeu apoio do Conselho Nacional de Desenvolvimento Científico e Tecnológico por meio de uma Bolsa de produtividade e do Programa de Excelência Acadêmica da Coordenação de Aperfeiçoamento de Pessoal de Nível Superior.

a Universidade Federal da Fronteira Sul, Chapecó, SC, Brasil.

b Universidade do Vale do Rio dos Sinos, São Leopoldo, RS, Brasil.

Recebido em: 08 fev. 2018

Aceito em: 17 out. 2019 
Dados sobre discriminação e violência contra grupos identitários específicos chegam a nós com frequência e são divulgados, periodicamente, em nosso país. Depois de, pelo menos, duas décadas de investimento em políticas públicas que visavam promover a paz e reduzir as práticas de discriminação e preconceito, ainda presenciamos dados alarmantes e acontecimentos como os narrados pelos fragmentos de pesquisas que abrem esses escritos. A discussão que apresentamos ao longo deste texto visa a problematizar as estratégias mobilizadas discursivamente a partir de uma ênfase nas identidades culturais, na Educação Escolar, a fim de reduzir as práticas de discriminação negativa (CASTEL, 2011). Entendemos que essas estratégias se articulam para constituir o que nominamos como governamento identitário.

A partir das análises dos materiais - seis produções que compõem a coleção Educação para Todos, organizada pelo Ministério da Educação (MEC) -, argumentamos que as políticas de atenção à diversidade operam sobre a população por meio do governamento identitário. As ações de governamento - alicerçadas no reconhecimento e no ordenamento identitário da população - agem a partir de duas estratégias principais: a produção da tolerância e a inversão do estigma (WIEVIORKA, 2002). Para defender nosso argumento, dividimos o texto em quatro partes. Na primeira parte, descrevemos os elementos que nos permitem problematizar a proliferação discursiva sobre as identidades culturais na Educação Escolar, a partir da ênfase na diversidade. Na segunda, apresentamos o governamento como conceito-ferramenta, inspirado nos Estudos Foucaultianos, para o exercício analítico que nos propomos empreender. Definimos, ainda, os contornos do que viemos caracterizando como governamento identitário e descrevemos o corpus de análise e as categorias analíticas. Os resultados e discussões aparecem na terceira parte, onde problematizamos a produção da tolerância como estratégia de governamento identitário e as principais táticas que a fazem operar, no cenário instituído por meio de uma racionalidade inclusiva; bem como tensionamos a produção de referentes positivos que visam a deslocar alguns grupos identitários de posições de degradação. Entender como essa estratégia se articula com a produção da tolerância e os efeitos que produz sobre a Educação nos parece crucial para compreender algumas manifestações sociais desse tempo. Por fim, na parte quatro, fazemos as considerações finais e levantamos alguns elementos que nos possibilitam outras leituras sobre a Educação na Contemporaneidade.

\section{A produção da diversidade na Educação brasileira}

Sendo tão grandes os problemas do convívio com a diferença, não poderia haver uma solução única ou completa

(SENNETT, 2012, p. 15). 
O convívio com as diferenças tem mobilizado uma multiplicidade de esforços no campo educacional, ao longo dos últimos anos, em diversas partes do mundo. No Brasil, um conjunto heterogêneo de fontes constitui o que se convencionou chamar de políticas de atenção à diversidade e busca orientar as práticas educacionais direcionadas à diferença, desde uma perspectiva pautada na "superação das desigualdades educacionais, com ênfase na promoção da cidadania e na erradicação de todas as formas de discriminação" (BRASIL, 2014, s/p), como aponta uma das diretrizes do Plano Nacional de Educação (PNE) 2014-2024. Entender como as questões relacionadas à diferença - assumida, no âmbito deste texto, como identidade cultural - passaram a compor um conjunto de políticas de atenção à diversidade, constituiu o mote de uma pesquisa maior e instrumentaliza as problematizações empreendidas ao longo deste texto.

$\mathrm{Na}$ atualidade, a utilização do termo identidade tem-se pulverizado em uma multiplicidade de discursos e configurado aspectos importantes da vida dos indivíduos, convocando-os a manifestar algumas marcas que traduzam seus pertencimentos identitários. A emergência desse tema na agenda política do Estado remonta à segunda metade do século XX. No entanto, dados os limites desse texto, circunscrevemos a análise ao período que se estende desde o ano de 2005 até 2015 - período que corresponde aos anos de publicação dos documentos analisados. Destacamos que o tema transversal Pluralidade Cultural, produzido no âmbito dos Parâmetros Curriculares Nacionais em 1997, já atribuía centralidade às diferenças culturais no campo da Educação, orientando sobre a necessidade de respeito às especificidades de cada grupo identitário, na dinâmica escolar. A produção deste documento se inscreve no cenário de emergência de uma racionalidade inclusiva - que vem tomando forma desde os últimos anos do século XX. Por meio dela, a Educação passou a ser acionada como engrenagem capaz de, pela ênfase nas identidades culturais, reduzir as desigualdades socioeconômicas e esmaecer as práticas de discriminação negativa, direcionadas a distintos grupos identitários, criando as condições para que todos participem das tramas sociais.

A Lei de Diretrizes e Bases da Educação (LDB) no 9.394/1996 (BRASIL, 1996), em seu artigo 26, a partir de redação dada pela Lei $n^{\circ} 12.796 / 2013$, orienta sobre a necessidade de considerar-se as características geográficas e humanas, em sua diversidade, na composição dos currículos escolares. Nessa direção, Sierra (2013, p. 36) sinaliza que, a partir dos anos 2000, o "apelo à diversidade não deixa mais de povoar nossos espaços discursivos de uma maneira bastante insistente e onipresente. Difícil é, hoje em dia, não encontrar essa palavra no vocabulário político, social, cultural, midiático e, principalmente, educacional". Escolarizar, na Contemporaneidade, significa, além de instrumentalizar os indivíduos para a inserção no jogo econômico (LOPES, 2009), produzir as condições para conviver em uma sociedade plural. 
Nesse registro, deixamos de olhar para as identidades unicamente pela representatividade cultural de certos grupos, para entendê-las como categorias políticas na articulação de práticas que permitam alcançar outras formas de vida, inacessíveis a esses grupos em tempos passados, e ordenar a população. As identidades constituem, assim, signos de lutas que reclamam respeito a determinados conjuntos de características. Elas assinalam diferenças entre os grupos, nos modos de conduzir suas condutas, e pedem acesso igualitário aos bens produzidos pela humanidade e à livre circulação na sociedade, sem ter de abrir mão dessas características, que as conformam culturalmente. A partir dos achados nos materiais analisados, olhamos para as identidades como representações de parcelas da população, dentro do espectro do que se convencionou chamar de diversidade. A base metodológica que possibilitou essa compreensão sobre as identidades será descrita na sequência.

\section{Dos contornos metodológicos}

As práticas regulatórias procuram governar indivíduos de uma maneira mais vinculada à sua subjetividade do que em qualquer

outro momento, e os conceitos de identidade e seus cognatos adquiriram uma maior relevância em muitas das práticas em que os seres humanos se envolvem (ROSE, 2011, p. 234).

O conhecimento das práticas culturais que caracterizam cada grupo permite delimitar as margens de suas ações e de suas demandas, mapeando modos de vida e inscrevendo neles certos tipos de indivíduos. Conhecer as diferentes parcelas da população que compõem a sociedade civil (FOUCAULT, 2008a) é crucial para agrupá-las, a partir de características que possam aproximar os indivíduos, delimitar suas diferenças e permitir o governamento identitário. Foucault (2008a, p. 258) descreve o governamento como "a maneira como se conduz a conduta dos homens". Pautamo-nos nesse conceito como ferramenta ${ }^{1}$ analítica e, a partir dele, definimos o governamento identitário como um tipo específico de governamento, que se serve das diferentes identidades para posicionar os indivíduos em pontos específicos da malha social e, pelo conhecimento das características que compõem certos modos de vida, melhor governar a população.

Ao conduzir práticas governamentais pelas identidades, o Estado brasileiro criou as condições para que diferentes agências passassem a operar estratégias de condução das condutas guiadas por elas. Nesta pesquisa qualitativa, olhamos

Por ferramenta, caracterizamos o conceito utilizado para trabalhar com os materiais, pautadas na discussão de Foucault (2006), em entrevista com Gilles Deleuze, sobre a produtividade de um conceito como ferramenta para mobilizar o pensamento. 
para a escola como uma das agências que produzem, nos indivíduos, as condições para a participação social. Nos materiais analisados, a ênfase nas identidades tenta colocar em operação uma série de estratégias que visam reduzir a discriminação e a desigualdade e produzir as condições para que os diferentes grupos possam participar das tramas sociais.

Para problematizar as estratégias de governamento identitário, selecionamos um conjunto de materiais que circulam na Educação e que, a partir de distintas frentes, instrumentalizam políticas educacionais. A superfície analítica foi produzida a partir de seis materiais organizados pela extinta Secretaria de Educação Continuada, Alfabetização, Diversidade e Inclusão (Secadi), em conjunto com a Organização das Nações Unidas para a Educação, a Ciência e a Cultura (Unesco), e disponibilizados na página eletrônica do Ministério da Educação (MEC). Constituído por uma coletânea de textos direcionados aos professores, esse conjunto de materiais traz resultados de pesquisas e orientações dispostas em uma multiplicidade de documentos legais, que orientam práticas educacionais. Os títulos dos materiais são: 1) Ações afirmativas e combate ao racismo nas Américas; 2) Diversidade sexual na Educação: problematizações sobre a homofobia nas escolas; 3) Educação como exercício de diversidade; 4) Educação na diversidade: como indicar as diferenças?; 5) Gênero e diversidade na escola: formação de professoras/es em Gênero, Orientação Sexual e Relações Étnico-Raciais, e; 6) O índio brasileiro: o que você precisa saber sobre os povos indígenas no Brasil de hoje. Entendemos que os discursos materializados nesses documentos traduzem a atmosfera desejada para as práticas educacionais nos primeiros anos do século XX. Dito de outro modo, nesse conjunto de materiais, encontramos fragmentos discursivos importantes na constituição das políticas de atenção à diversidade. Eles estão, portanto, compreendidos dentro do conjunto heterogêneo de materiais que articulam as políticas de atenção à diversidade e, por isso, foram escolhidos para a análise.

Após o manuseio dos materiais e das muitas tentativas de categorização, percebemos, pela recorrência enunciativa (FOUCAULT, 2008b) - agrupando excertos cujos sentidos se aproximavam - duas estratégias de governamento identitário, que compõem os resultados desta pesquisa: a produção da tolerância e a inversão do estigma (WIEVIORKA, 2002). A primeira se desdobra em três táticas principais: o conhecimento do outro; o respeito às diferenças, e a convivência entre os grupos identitários. A segunda se produz a partir da criação de marcas identitárias positivas e do reconhecimento e da valorização coletiva das marcas culturais de certos grupos identitários, como táticas principais. Os resultados e as discussões, na forma de estratégias e táticas encontradas em cada uma das categorias analíticas, serão desdobrados na próxima seção, 
trazendo fragmentos dos materiais, ora incorporados ao texto, ora agrupados em blocos organizados por proximidades de sentido.

\section{Resultados e discussões}

Desde, pelo menos, a última década do século XX, a Educação escolarizada passou a assumir papel importante na constituição de uma cultura de paz. Depois de duas grandes guerras mundiais, que transformaram em cinzas cidades inteiras, as Nações Unidas incluíram a tolerância - fixada como respeito entre os povos e às distintas culturas - como meta para que cada nação contribua com a produção de um cenário de paz mundial. Em um estudo que persegue o conceito de tolerância, desde a Renascença até a Contemporaneidade, Souza (2006, p. 151), afirma que ela "não é uma virtude ou uma atitude primeira, mas uma reação defensiva e necessária diante da intolerância, que com frequência é assassina no seu ódio à diversidade alheia". Nesse registro, é possível inferir que a tolerância emerge, nos discursos educacionais, como uma reação à multiplicidade de práticas de intolerância desencadeadas nas relações sociais e diante dos horrores provocados pela violência e pela guerra, embora a reconheçamos como uma estratégia liberal que, muitas vezes, acentua dicotomias existentes.

A tolerância assumiu os contornos de uma habilidade a ser constituída pelos países membros da Organização das Nações Unidas (ONU), a partir do ano de 1995 - com a publicação da Declaração de princípios sobre a tolerância. Ela foi gradativamente incorporada pelas políticas educacionais e passou a orientar práticas no campo da Educação. Para Souza (2006), a ONU vem se esforçando, desde a Declaração Universal dos Direitos Humanos (1948), para constituir uma centralidade para a tolerância no cenário mundial, por meio de uma agenda política que faça dela uma pauta comum a todas as nações. Segundo ele, a tolerância, nos documentos que a circunscrevem, afasta-se de uma posição de passividade e tenta afirmar uma "postura positiva e propositiva" (SOUZA, 2006, p. 119), nas relações entre diferentes identidades culturais. Sua promoção passa a constituir uma das responsabilidades da Educação, que constitui o "meio mais eficaz de prevenir a intolerância" (UNESCO, 1995, p. 15). Nesse registro, a tolerância emerge como garantia para a convivência em uma sociedade organizada e produzida por diferenças.

Para Burbules (2012, p. 178-179), referir à "posição pluralista de tolerância à diversidade [...] significa acomodação daquelas características da diferença que podem ser compreendidas e classificadas em termos dos modelos dominantes, ignorando ou negligenciando outras espécies de diferença". Nesse registro, o outro é sempre condenado a ser mais parecido com um padrão estabelecido como dominante e passa 
a ser visto e avaliado a partir dele, na ordem da normalidade. A tolerância, aqui, ficaria circunscrita à condição de igualdade ou de proximidade ao igual. Gomes (2005, p. 237), assinala que "a escola impõe padrões de currículo, de conhecimento, de comportamentos e também de estética. Para estar dentro da escola é preciso apresentar-se fisicamente dentro de um padrão, uniformizar-se". Aqui aparece uma das tensões provocadas pela diversidade na Educação. Ao produzirem-se, a partir de práticas que não seguem a mesma linha do discurso dominante (TOURAINE, 2009), as diferentes identidades culturais que passam a habitar a escola, desacomodam algumas práticas escolares e, como sinaliza Junqueira (2009), exigem outros referentes que possam orientá-las, mobilizados pelo respeito às diferenças.

A sistematização e a análise das enunciações presentes no material de pesquisa apontaram para três táticas principais, operadas na Educação Escolar pela ênfase na tolerância, sejam elas: o conhecimento do outro; o respeito às diferenças, e; a convivência entre os grupos identitários. Termos como descoberta, respeito e valorização circulam com facilidade nas orientações do MEC, para o exercício da docência, desde a última década do século XX. No Brasil, a publicação dos Parâmetros Curriculares Nacionais (PCN), em 1997, marca a aparição da tolerância e do respeito ao outro como fins educacionais. Segundo esse documento, "o trabalho com Pluralidade Cultural se dá a cada instante, exige que a escola alimente uma 'Cultura da Paz', baseada na tolerância, no respeito aos direitos humanos e na noção de cidadania compartilhada por todos os brasileiros" (BRASIL, 1997, p. 117). Ao assumir o compromisso com a tolerância, as políticas educacionais brasileiras primam pela articulação entre discursos e materiais (preferencialmente direcionados aos professores), que viabilizem o conhecimento do outro, do diferente, de modo a, pelas redes de conhecimento, promover a aproximação e a convivência entre os escolares.

A produção de conhecimentos sobre a diferença, como tática para a instituição da tolerância, fica clara na definição da Educação para a diversidade, como responsável por introduzir “no processo pedagógico o conhecimento do 'outro', pois uma das formas mais resilientes do preconceito e da exclusão é o desconhecimento do distinto e do diferente" (TELES; FRANCO, 2006, p. 58). Ao definir e nomear os indivíduos e os grupos aos quais se vinculam, a escola mapeia e circunscreve as diferenças que a compõem. Conhecer os indivíduos, seus hábitos, seus gostos, torna a convivência possível, por meio de uma aproximação segura, dentro de um espaço limitado e regido por regras específicas, como a escola. Ao delinear a possibilidade de uma convivência pacífica, as políticas educacionais objetivam imprimir, nos indivíduos, um tipo de confiança que faz com que se tornem mais propensos a admitir e tolerar as diferenças, produzindo, em certa medida, uma sociedade capaz de conviver com elas. 
A centralidade no respeito à diversidade aparece com frequência nos materiais. Para mostrá-la selecionamos dois excertos que caracterizam a articulação entre o respeito à diversidade e à qualidade do processo educativo. Para Henriques e Cavalleiro (2005, p. 223) "a Educação de qualidade para todos passa, na realidade brasileira, pelo respeito e valorização da diversidade étnico-racial, cultural, de gênero, de orientação sexual, social e regional e, portanto, pela construção de instrumentos que assegurem, nos sistemas de ensino, o direito à diferença". Junqueira (2009, p. 404), segue na mesma direção, ao sinalizar que "o respeito à diversidade é elemento imprescindível para se garantir a formação para cidadania e a qualidade do processo de ensino-aprendizagem - convém repetir, em favor de cada pessoa". Independentemente do grupo a que se refira, parece haver um consenso sobre a necessidade de produção de uma atmosfera de respeito às diferenças, na escola. Valorizar cada uma das diferenças, por longo tempo inferiorizadas, parece fundamental para que possam sentir-se acolhidas. A operacionalização do respeito à diferença requer a valorização dos indivíduos pertencentes a grupos identitários historicamente discriminados, a partir da equiparação do valor de cada uma das identidades culturais que compõem a diversidade.

Nos materiais analisados, a convivência entre os grupos identitários emerge como uma terceira tática operada pela ênfase na tolerância. Como foi projetado desde a idealização de uma Educação para o século XXI (DELORS et al., 1998), a criação das condições para uma convivência pacífica configura um investimento necessário para a Educação na diversidade. Vieira Junior (2005, p. 96) destaca que, "no multiculturalismo objetiva-se a convivência entre diferentes. Diferentes 'raças', etnias, valores, costumes, hábitos, religiões e culturas em que se tenta extrair a partir do diálogo das diferenças pontos de convergência que impulsionem o desenvolvimento das nações". Essa convivência entre as diferenças é nominada por Junqueira (2009, p. 411) como existência compartilhada. Para ele,

a Educação na, para e pela diversidade [...] procura dizer respeito ao aprendizado da existência compartilhada, pacífica, cidadã e democrática, além de possuir um papel estratégico na promoção do diálogo permanente voltado para garantir igualdade de oportunidades, inclusão e integração social e o desfazimento das condições de reprodução de iniqüidades materiais e simbólicas.

Com base nesses excertos, entendemos que a possibilidade de convivência, num cenário composto por diferenças, aparece associada a uma concepção de existência compartilhada. Esposito (2007, p, 157) afirmou que "a existência é 'com', comexistência, ou não existe. $\mathrm{O}$ cum não é algo que se agregue desde o exterior ao 
ser da existência. É precisamente o que a faz ser quem é". Para ele, "a existência só pode conjugar-se em primeira pessoa do plural: nós somos" (ESPOSITO, 2007, p. 157). Pensar a existência no âmbito da Educação, presume um coletivo de indivíduos que habita o espaço escolar. A existência nesse espaço obriga a convivência entre eles, por meio da participação de uma série de atividades comuns, previstas para o ano escolar em que se encontram matriculados. Para evitar a inexistência de alguns outros - que se traduz na invisibilidade de certos indivíduos ou grupos na Educação - e para evitar a constituição de relações do tipo "nós-contra-eles" (SENNETT, 2012, p. 13), as políticas de atenção à diversidade interrogam pela habilidade da Educação para estabelecer o diálogo.

Nesse caminho, rastreamos uma série de investimentos, de documentos e regulamentações legais que, há mais de duas décadas, vêm orientando e prescrevendo uma Educação para a tolerância, como estratégia eficaz para reduzir as práticas de discriminação. $\mathrm{O}$ rastreio e a análise desses materiais nos fizeram voltar ao início dessa parte e interrogar novamente: por que seguimos assistindo à propagação dessas práticas discriminatórias em uma multiplicidade de espaços sociais, noticiada todos os dias por diversos veículos de comunicação, bem como por um volume considerável de quadros estatísticos que as colocam em evidência? Será a Educação para a tolerância estratégia suficiente para esmaecer o seu reverso - a intolerância?

Essas questões nos levaram a seguir operando com os materiais, redirecionando o olhar para uma segunda estratégia de governamento identitário: a inversão do estigma. A produção de uma base tolerante para a Educação é condição necessária para a inversão do estigma, pois é pelo conhecimento, pelo respeito à diferença e pela convivência - como táticas operadas desde uma ênfase na tolerância - que se poderá produzir referentes positivos na relação dos indivíduos consigo mesmos e com os outros. Da mesma forma, a inversão do estigma faz operar táticas fundamentais para a produção da tolerância. É pela constituição de referentes positivos, que possibilitem a equiparação entre as culturas, que o respeito entre elas será potencializado. Desse modo, o núcleo de uma Educação na diversidade - que serve ao governamento identitário - produz-se no cruzamento entre essas estratégias.

Importa marcar que, nas relações pautadas pelo estigma, o indivíduo estigmatizado é desautorizado a ser qualquer coisa diferente daquilo que o estigma possa informar sobre ele (GOFFMAN, 1988). Perceber que essas marcas seguem definindo relações na Contemporaneidade informa sobre a permanência de práticas orientadas por uma racionalidade excludente no que se refere a determinados grupos identitários, 
produzindo um afastamento entre os indivíduos, potencializado pelas marcas visibilizadas por alguns grupos. Parece-nos possível dizer que tal racionalidade vem intensificando efeitos, sobretudo pela onda conservadora que, nos últimos anos, vem tomando partes específicas do mundo, como alguns países da Europa, Estados Unidos e Brasil. Nesse contexto, problematizar os contornos estabelecidos no conjunto dos materiais de análise, para inverter os estigmas que conformam relações escolares, pela via cultural, parece-nos necessário.

"Promover, por meio da Educação, uma tomada de consciência do valor positivo da diversidade cultural e aperfeiçoar, com esse fim, tanto a formulação dos programas escolares como a formação dos docentes" (UNESCO, 2002, p. 06), constitui um dos objetivos assumidos pelos países signatários da Declaração Universal sobre a Diversidade Cultural (UNESCO, 2002). Olhar para o outro pela via cultural não é o mesmo que olhá-lo a partir de uma hierarquia que o posiciona um degrau abaixo. Uma mudança de concepção parece implícita nesse deslocamento, reposicionando os indivíduos que olham e os que são olhados, a partir de perspectivas que admitam a atribuição de uma potência aos grupos por longo tempo discriminados. Entendemos que, para que a diferença encontrasse lugar na escola, a persecução desse outro modo de ver os grupos discriminados negativamente assumiu um papel central, por possibilitar o acesso a bens e espaços sociais e por fazer crer na produção de um olhar de potência sobre eles.

Nesse registro, as discussões de Wieviorka (2002), sobre a inversão do estigma, ajudam-nos a compreender as políticas de atenção à diversidade, especialmente no que refere às estratégias traçadas para reduzir as práticas de discriminação. Inverter o estigma constitui um elemento central para esse fim. Para Wieviorka (2002, p. 39), pela inversão do estigma, "uma identidade até então escondida, recalcada, mais ou menos envergonhada ou reduzida à imagem de uma natureza se transforma em afirmação cultural visível ou assumida”. Para ele, essa inversão potencializa a existência de certos indivíduos ou grupos, pois é o "princípio de identidade positiva que autoriza o respeito próprio e a esperança no futuro" (WIEVIORKA, 2002, p. 45). Distintos grupos identitários sofreram estigmatizações, mais ou menos, semelhantes, que lhes conferiram uma cidadania de segunda classe, ao longo da história, pela supressão de direitos e pela omissão do Estado. Nesse registro, produzir outros referentes, que instrumentalizem as relações entre os indivíduos, parece fundamental para que a escola obtenha êxito na tarefa de educar na diversidade.

A inversão do estigma (WIEVIORKA, 2002) pressupõe duas condições fundamentais, entendidas - no âmbito desse texto - como táticas que fazem operar essa estratégia de governamento identitário: 1) a atribuição de uma 
marca positiva que mobilize um conjunto de indivíduos na orientação de suas condutas e os impulsione a sair de uma condição de degradação social, e 2) o reconhecimento e a valorização coletiva das marcas culturais de certos grupos, com vistas a produzir um outro modo de olhar para e de relacionar-se com eles. Desse modo, "a inversão do estigma comporta necessariamente duas dimensões entrelaçadas [...] trabalho do actor sobre si próprio e confronto com a sociedade, reação perante o olhar de invalidação que aquela fazia incidir sobre ele até então, ou que ele assim percebia" (WIEVIORKA, 2002, p. 154).

Mohelecke (2009, p. 464) reitera a posição de Wieviorka (2002), ao sinalizar que "a luta pelo direito à diferença deve passar primeiro pela desconstrução da autoimagem negativa atribuída pelo colonizador a diferentes povos". Ainda segundo a autora, "a autodepreciação transforma-se no instrumento mais poderoso de opressão, e o principal objetivo desses grupos deve ser a libertação dessa forma destrutiva de identidade" (MOHELECKE, 2009, p. 464). Reverter esses quadros parece crucial para possibilitar a ativação dos grupos discriminados e a sua participação na vida coletiva. Para Gonçalves e Silva (2005, p. 209), essa reversão não se dá somente pela escolarização, mas envolve a produção de "uma radical revisão dos mapas culturais, que as elites e, por consequência, os currículos escolares, elaboraram sobre o povo brasileiro", ou seja, não basta que os grupos produzam um olhar positivo para si, se esse mesmo olhar não encontrar espaço no meio social. Caso a positivação não se produza socialmente, as relações entre os grupos seguirão sendo pautadas pela inferiorização de práticas culturais específicas e dos indivíduos que as colocam em circulação.

A positivação das identidades culturais é descrita, no conjunto dos materiais, como tarefa necessária para a Educação na diversidade, o que pode ser percebido nos excertos que seguem.

O processo de reafirmação da identidade indígena e o sentimento de orgulho de ser índio estão ajudando a recuperar gradativamente a autoestima indígena perdida ao longo dos anos de repressão colonizadora. Os dois sentimentos caros aos povos indígenas estão possibilitando a retomada de atitudes e de comportamentos mais positivos entre eles, diante de um horizonte sociocultural mais promissor e esperançoso. As atuais gerações indígenas nascem, crescem e vivem com um novo olhar para o futuro, potencialmente possível e alentador, diferente das gerações passadas que nasciam e viviam conscientes da tragédia do desaparecimento de seus povos. A reafirmação da identidade não é apenas um detalhe na vida dos 
povos indígenas, mas sim um momento profundo em suas histórias milenares e um monumento de conquista e vitória que se introduz e marca a reviravolta na história traçada pelos colonizadores europeus, isto é, uma revolução de fato na própria história do Brasil (LUCIANO, 2006, p. 42-43).

Estimular dinâmicas de relacionamento, de reconhecimento mútuo, aceitação e valorização do "outro", diálogo intercultural, de modo a favorecer a construção de um autoconceito e uma autoestima positivos em todos(as) os(as) alunos(as) constitui uma preocupação fundamental para se desenrolarem práticas educativas multiculturais (FÁVERO; IRELAND, 2005, p. 52).

Faz-se necessário contextualizar o currículo, "cultivar uma cultura de abertura ao novo, para ser capaz de absorver e reconhecer a importância da afirmação da identidade, levando em conta os valores culturais" dos/as estudantes e seus familiares, favorecendo que estudantes e educadores/as respeitem os valores positivos que emergem do confronto dessas diferenças, possibilitando, ainda, desativar a carga negativa e eivada de preconceitos que marca a visão discriminatória de grupos sociais, com base em sua origem étnicoracial, suas crenças religiosas, suas práticas culturais, seu modo de viver a sexualidade (BRASIL, 2009, p. 33).

Entender a Educação como campo em que se prolifera um conjunto de conhecimentos e que, como lugar privilegiado, pode cessar a difusão de certas concepções discriminatórias sobre o outro, a partir da invenção de uma positividade que o valoriza, parece constituir o elemento central que congrega esses excertos e perpassa o conjunto dos materiais. $\mathrm{O}$ foco, aqui, está em aprender a viver juntos e a valorizar o outro, a partir de relações de equivalência, entendendo que os indivíduos têm o mesmo valor, independentemente de seus pertencimentos identitários e das prováveis diferenças que venham a existir.

Olhar para si e para o seu grupo, a partir de uma perspectiva de futuro para as suas práticas culturais, como no caso dos indígenas, permite a produção de expectativas para a continuidade da própria vida, sem o assombro constante provocado pelo medo do extermínio de vidas e de propósitos. A definição negativa de indivíduos de um certo tipo inviabiliza a sua inserção e a sua participação social, pela pouca (ou nenhuma) expectativa criada sobre eles e por eles, paralisando-os. Inverter essa lógica parece crucial para a constituição de 
uma sociedade inclusiva, justa e democrática, anunciada em distintas políticas educacionais e para a produção de uma perspectiva de futuro.

Os PCN (1997) já indicavam a necessidade de reposicionar os grupos discriminados negativamente, a partir da decomposição dos estereótipos que os mantinham em estratos inferiores da hierarquia social, ao afirmar que a valorização da diversidade cultural brasileira "propicia ao aluno a compreensão de seu próprio valor, promovendo sua autoestima como ser humano pleno de dignidade" (BRASIL, 1997, p. 137). Nesse registro, Gadea (2013), também, descreve a constituição de referentes que mobilizam o movimento negro. Para ele, dentro do referido movimento "assumia-se a negritude como 'denominação negativamente conotada para reverter-lhe o sentido, permitindo assim que a partir de então as comunidades negras passassem a ostentála com orgulho e não mais com vergonha ou revolta"' (GADEA, 2013, p. 78).

$\mathrm{Na}$ esteira dessas discussões, parece-nos que, além de mobilizar o indivíduo a agir sobre si e estimular a ação do grupo contra uma desqualificação a ele atribuída, a escola opera sobre todos, conformando estratégias de governamento identitário, que visam forjar outros modos de perceber as identidades e de conviver com elas. Dito de outro modo, ao perpassar as práticas escolares, além de representar uma luta de um indivíduo ou de um grupo para minar um tipo de desqualificação, as identidades passam a mobilizar práticas pedagógicas que contribuam com essa inversão, no coletivo.

Pelo exercício analítico empreendido até aqui, entendemos que há uma clara sinalização sobre o papel da escola em reduzir os estranhamentos entre as diferenças, a partir da desativação de uma carga negativa que marca alguns grupos identitários. Há duas décadas, essa vem sendo uma tarefa desenhada para a Educação, que se prolifera nos discursos educacionais; faz-se ver nos programas de formações de professores, nos materiais didáticos e nos projetos e diretrizes que organizam a vida escolar. No entanto, parece-nos que a inversão do estigma só alcança um resultado parcial, que permite a constituição de direitos para os grupos, possibilitando o acesso aos bens e espaços sociais, mas não produz o efeito positivo sobre a coletividade, fazendo com que os grupos identitários continuem sendo olhados a partir de uma marca negativa. Wieviorka (2002) destaca que a mobilização do grupo sobre si, precisa vir acompanhada de uma capacidade social de legitimar a positivação de seus marcadores culturais.

Se a sociedade é indiferente ao discurso da consciência orgulhosa, se não se apercebe dela ou, pior, não pode deixar de a considerar mítica, então a inversão que a produziu representa o risco de isolar o actor na 
loucura, na autodestruição ou no sectarismo, em vez de lhe permitir a construção de um lugar reconhecido na vida colectiva. A inversão do estigma só evita estes efeitos devastadores se for acompanhada pela capacidade por parte dos actores de se fazerem ouvir e pela capacidade, por parte da sociedade de os escutar (WIEVIORKA, 2002, p. 160).

Depreende dessa discussão que a inversão do estigma só se completa no cruzamento entre as capacidades de o indivíduo produzir um olhar positivo sobre si e de mobilizar uma escuta social, que instrumentalize a produção de um outro olhar sobre a sua identidade, pelos outros. Como a produção desse olhar positivo, desde o coletivo, ainda se caracteriza por iniciativas isoladas e esporádicas, seguimos observando uma multiplicidade de práticas que se orientam pela lógica da discriminação. Se a inversão do estigma e a produção da tolerância, como estratégias que visam o esmaecimento de práticas de discriminação, produzem-se numa relação de interdependência, em não se produzindo uma, a outra também não se completa. Nesse ciclo, a Educação acaba por colocar em circulação uma série de discursos que delineiam objetivos pouco materializados no cotidiano escolar e que continuam a fazer ressoar os discursos dominantes. Colocadas dessa forma, as estratégias de governamento identitário produzem um efeito ricochete sobre as práticas de discriminação.

\section{Para seguir pensando}

Ao longo deste texto, buscamos mostrar como a produção da tolerância e a inversão do estigma são produzidas como estratégias de governamento identitário, que organizam e prescrevem práticas no campo da Educação. Acreditamos que a fixação das identidades culturais constitui uma estratégia bastante eficaz para o governamento, pois determina conjuntos populacionais; mapeia os modos de vida e regula as liberdades, a partir de um conjunto de conhecimentos, produzidos em parcerias estabelecidas entre o Estado e os grupos identitários (SIERRA, 2013). No entanto, ao produzir limites claros para cada grupo, ao cartografar e informar os pertencimentos identitários de cada um - definindo quem são e como tratar as diferenças - as políticas educacionais produzem limites, também, para os relacionamentos.

"Ligar corpos [...] a identidades e causas e dividir lugares e partes com base em interesses, preferências e opiniões é de fato uma constituição simbólica do social e instala um tipo particular de subjetivação governamental" (MASSCHELEIN; SIMONS, 2014, p. 141). Identificar e agrupar caracterizam, no registro do que pontuam os autores e do que viemos mostrando ao longo deste texto, meios para exercer o governamento. No entanto, o direcionamento dessas mesmas estratégias 
no campo educacional produz resultados que parecem se afastar da meta de redução das práticas de discriminação. Ao delimitar as identidades e circunscrever suas práticas culturais, a Educação parece estar produzindo mais distanciamento do que aproximação, atualizando o fosso entre as diferenças. Ao produzir a tolerância como estratégia de convivência; ao inverter parcialmente o estigma - limitando seus efeitos à positivação das práticas dentro de cada grupo -, as políticas de atenção à diversidade estabelecem limites identitários que acabam por ricochetear nas práticas de discriminação. Esse efeito se produz de modo aleatório e pouco contribui para o esmaecimento dessas práticas, pois se limita a rebatê-las. Nesse registro, mesmo que os indivíduos reconheçam, momentaneamente, a necessidade de produção de outros referentes que pautem as relações com a diversidade, as práticas, operadas nas relações cotidianas, seguem reproduzindo uma lógica de discriminação entre as diferenças.

Reconhecemos que os agrupamentos identitários garantem a mobilização dos grupos e o acesso a bens e serviços sociais, bem como garantem aos grupos um conjunto limitado de direitos, que atendem as suas necessidades específicas. Reconhecemos, também, que as identidades têm um papel importante na Educação escolar, ao instrumentalizar os grupos e ao possibilitar que mais indivíduos conheçam uma multiplicidade de práticas culturais. Entretanto, mesmo que sejam, constantemente, "instruídos a reconhecer as diferenças e proteger as minorias" (TOURAINE, 2009 , p. 14), os indivíduos raramente direcionam aos grupos discriminados um olhar de potência e seguem nutrindo a inferiorização das diferenças. Nessa esteira, ao olhar para as práticas de discriminação e violência percebemos que, na Contemporaneidade, os outros seguem sendo menos.

Desse modo, as identidades constituem critérios importantes na promoção do acesso à Educação e na instrumentalização dos indivíduos, com referentes que lhes permitam olhar para si, desde uma equiparação que os conduza a perceber e a operar relacionalmente, a partir de marcas positivas. Dito isso, satisfeitas as necessidades para a equiparação, parece-nos oportuno que a Educação deixe de se pautar pelos limites impostos pelas identidades culturais e perceba cada indivíduo em sua singularidade, de modo a instrumentalizar a todos, independentemente de seus vínculos identitários. Uma Educação transgressora, que se organize por uma pauta que ultrapasse as identidades e que não se prenda aos limites colocados por elas, soa-nos como uma possibilidade interessante para o tempo em que vivemos. 


\section{The identity government strategies in Education}

\section{Abstract}

The text problematizes the identity government strategies operated in Education, in the Contemporaneity. In the intersection between Michel Foucault's studies and theorizations that are based on contemporary social thought, it articulates governance as a tool for the analytical exercise produced on six publications of the Ministry of Education, which make up the Education for All collection. It shows two identity governance strategies, outlined in educational policies: the tolerance production and the stigma inversion, which take on the purpose, the fading of discrimination practices. Finally, it concludes that the partial stigma inversion precludes the incorporation of tolerance in the relationships between individuals, making that these strategies do not produce the expected effects.

Keywords: Cultural identity. Tolerance. Discrimination. Education.

\section{Las estrategias de gobiernamento identitaria em la Educación}

\section{Resumen}

El texto problematiza las estrategias de gobiernamento identitaria operadas en la Educación, en la Contemporaneidad. En la intersección entre los estudios de Michel Foucault y teorizaciones que están afiliadas al pensamiento social contemporáneo, se articula la gobiernamento como una herramienta para el ejercicio analítico, producido en seis publicaciones del Ministerio de Educación, que componen la colección Educación para Todos. Muestra de dos estrategias de gobiernamento identitaria descritas en las políticas educativas: la producción de tolerancia y la inversión del estigma, que asumen, como un fin, el desvanecimiento de las prácticas de discriminación. Finalmente, se concluye que la inversión parcial del estigma hace que sea imposible incorporar tolerancia en las relaciones entre individuos, evitando así que estas estrategias produzcan los efectos esperados.

Palabras clave: Identidad cultural. Tolerancia. Discriminación. Educación. 


\section{Referências}

AZEVEDO, R.; BRETAS, V. Um retrato da violência contra homossexuais no Brasil. Exame, São Paulo, 29 maio 2016. Disponível em: http://exame.abril. com.br/brasil/um-retrato-da-violencia-contra-homossexuais-no-brasil/. Acesso em: 29 nov. 2016.

BRASIL. Lei n ${ }^{\circ}$ 9.394, de 20 de dezembro de 1996. Eestabelece as diretrizes e bases da educação nacional. Diário Oficial da União, Brasília, DF, 23 dez. 1996.

BRASIL. Lei n ${ }^{\circ} 13.005$, de 25 de junho de 2014. Aprova o Plano Nacional de Educação - PNE e dá outras providências. Diário Oficial da União, Brasília, DF, 26 jun. 2014.

BRASIL. Ministério da Educação. Gênero e diversidade na escola: formação de professoras/es em gênero, orientação sexual e relações étnico-raciais. Rio de Janeiro, RJ: CEPESC; Brasília, DF: SPM, 2009.

BRASIL. Ministério da Educação. Parâmetros curriculares nacionais: pluralidade cultural. Brasília, DF: Secretaria de Educação Fundamental, 1997.

BURBULES, N. C. Uma gramática da diferença: algumas formas de repensar a diferença e a diversidade como tópicos educacionais. In: GARCIA, R. L.; MOREIRA, A. F. B. Currículo na contemporaneidade: incertezas e desafios. São Paulo: Cortez, 2012. p. 175-206.

CASTEL, R. A discriminação negativa: cidadãos ou autóctones? Petrópolis: Vozes, 2011.

DEBELAK, C. D.; DIAS, L. D.; GARCIA, M. Feminicídio no Brasil: a cultura de matar mulheres. Disponível em: http://feminicidionobrasil.com. br/\#expediente. Acesso em: 29 nov. 2016.

DELORS, J. et al. Educação: um tesouro a descobrir: relatório para a Unesco da Comissão Internacional sobre Educação para o século XXI. Brasília, DF: Unesco, 1998.

ESPOSITO, R. Communitas: origen y destino de la comunidad. Buenos Aires: Amorrortu, 2007.

FÁVERO, O.; IRELAND, T. D. (org.). Educação como exercício de diversidade. Brasília, DF: Unesco, MEC, 2005. 
FOUCAULT, M. A arqueologia do saber. Rio de Janeiro: Forense Universitária, 2008b.

FOUCAULT, M. Nascimento da biopolítica: curso dado no Collège de France (1978-1979). São Paulo: Martins Fontes, 2008a.

FOUCAULT, M. Os intelectuais e o poder. In: FOUCAULT, M. Ditos e escritos IV. Rio de Janeiro: Forense Universitária, 2006. p. 371-376.

GADEA, C. A. Negritude e pós-africanidade: críticas das relações raciais contemporâneas. Porto Alegre: Sulina, 2013.

GOFFMAN, E. Estigma: notas sobre a manipulação da identidade deteriorada. Rio de Janeiro: LTC, 1988.

GOMES, N. L. Trajetórias escolares, corpo negro e cabelo crespo: reprodução de estereótipos ou ressignificação cultural? In: FÁVERO, O.; IRELAND, T. D. (org.). Educação como exercício de diversidade. Brasília, DF: Unesco, MEC, 2005. p. 229-250.

GONÇALVES, L. A. O.; SILVA, P. B. G. Movimento negro e educação. In: FÁVERO, O.; IRELAND, T. D. (orgs.). Educação como exercício de diversidade. Brasília, DF: Unesco, MEC, 2005. p. 181-228.

HENRIQUES, R.; CAVALLEIRO, E. Educação e políticas públicas afirmativas: elementos da agenda do Ministério da Educação. In: SANTOS, S. A. (org.). Ações afirmativas e combate ao racismo nas Américas. Brasília, DF: Unesco, 2005. p. 209-24.

JUNQUEIRA, R. D. Educação e homofobia: o reconhecimento da diversidade sexual para além do multiculturalismo liberal. In: JUNQUEIRA, R. D.

Diversidade sexual na educação: problematizações sobre a homofobia nas escolas. Brasília, DF: Secad, Unesco, 2009. p. 367-444.

LOPES, M. C. Políticas de inclusão e governamentalidade. Educação \& Realidade, Porto Alegre, v. 34, n. 2, p. 153-169, maio-ago. 2009. Disponível em: https://seer. ufrgs.br/educacaoerealidade/article/view/8297/5536. Acesso em: 16 nov. 2017.

LUCIANO, G. S. O indio brasileiro: o que você precisa saber sobre os povos indígenas no Brasil de hoje. Brasília, DF: Secad, 2006.

MASSCHELEIN, J.; SIMONS, M. A pedagogia, a democracia, a escola. Belo Horizonte: Autêntica, 2014. 
MOHELECKE, S. As políticas de diversidade na educação no governo Lula. Cadernos de Pesquisa, São Paulo, v. 3, n. 137, p. 461-487, maio/ago. 2009. https://doi.org/10.1590/S0100-15742009000200008

ROSE, N. Inventando nossos selfs: psicologia, poder e subjetividade. Petrópolis: Vozes, 2011.

SENNETT, R. Juntos: os rituais, os prazeres e as políticas de cooperação. Rio de Janeiro: Record, 2012.

SIERRA, J. C. Marcos da vida viável, marcas da vida vivível: o governamento da diversidade sexual e o desafio de uma ética/estética pós-identitária para a teorização político-educacional LGBT. 2013. Tese (Doutorado em Educação) - Programa de Pós-Graduação em Educação, Universidade Federal do Paraná, Curitiba, 2013.

SOUZA, M. G. A. Tolerar é pouco? Por uma filosofia da educação a partir do conceito de tolerância. 2006. Tese (Doutorado em Educação) - Programa de Pós-Graduação em Educação, Pontifícia Universidade Católica do Rio de Janeiro, Rio de Janeiro, 2006.

TELES, J. L. T.; FRANCO, C. T. S. (orgs.). Educação na diversidade: como indicar as diferenças? Brasília, DF: Secad, 2006.

TOURAINE, A. Pensar outramente o discurso interpretativo dominante. Petrópolis: Vozes, 2009.

UNESCO. Declaração de princípios sobre a tolerância. Brasília, DF, 1995.

UNESCO. Declaração universal sobre a diversidade cultural. Brasília, DF, 2002.

VIEIRA JÚNIOR, R. J. Rumo ao multiculturalismo: a adoção compulsória de ações afirmativas pelo Estado brasileiro como reparação dos danos atuais sofridos pela população negra. In: SANTOS, S. A. (org.). Ações afirmativas e combate ao racismo nas Américas. Brasília, DF: Unesco, 2005. p. 83-101.

WELLE, D. A guerra diária do Brasil contra os jovens. Carta Capital, São Paulo, 21 out. 2015. Disponível em: http://www.cartacapital.com.br/sociedade/ a-guerra-diaria-do-brasil-contra-os-jovens.html. Acesso em: 29 nov. 2016.

WIEVIORKA, M. A diferença. Lisboa: Fenda, 2002. 


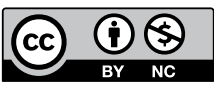

\section{Informações das autoras}

Patrícia Gräff: Doutora em Educação. Docente do Programa de Pós-Graduação em Educação da Universidade Federal da Fronteira Sul. Líder do Grupo de Pesquisa em Políticas e Práticas de Inclusão da mesma universidade, apoiado pelo Conselho Nacional de Desenvolvimento Científico e Tecnológico. Contato: patricia.graff@uffs.edu.br

iD https://orcid.org/0000-0002-3315-2401

Maura Corcini Lopes: Doutora em Educação. Docente do Programa de Pós-Graduação em Educação da Universidade do Vale do Rio dos Sinos. Pós-Doutorado pela Universidade de Lisboa. Líder do Grupo de Estudo e Pesquisa em Inclusão da mesma universidade. Bolsista de Produtividade em Pesquisa do Conselho Nacional de Desenvolvimento Científico e Tecnológico. Contato: maura@unisinos.br

(iD) https://orcid.org/0000-0002-2419-9208 